\title{
LACK OF FIDGETY MOVEMENTS AT 15 WEEKS POST-TERM RELATES TO CEREBRAL PALSY AND ADVERSE COGNITIVE OUTCOME IN PRETERM BORN CHILDREN AT 10 YEARS OF AGE
}

K. Hermansen Grunewaldt ${ }^{1,2}$, T. Fjørtoft ${ }^{3}$, G.C.C. Løhaugen ${ }^{1,4}$, K.A.I. Evensen ${ }^{3,5}$, A.-M. Brubakk ${ }^{1,2}$, J. Skranes ${ }^{1,2,4}$

${ }^{I}$ Dept of Lab. Medicine, Children's and Women's Health, Norwegian University of Science and Technology,

${ }^{2}$ Dept of Paediatric, ${ }^{3}$ Dept of Clinical Services, St. Olav's University Hospital, Trondheim, ${ }^{4}$ Dept of Pediatrics, Sørlandet Hospital, Arendal, ${ }^{5}$ Dept of Public Health and General Practice, Norwegian University of Science and Technology, Trondheim, Norway

Background and aims: The General-Movement-Assessment (GMA) is a powerful predictor of later neurological outcome in preterm infants. We wanted to determine whether GMA status during the Fidgety period at 15 weeks post-term, in preterm children can predict motor and cognitive outcomes at age 10.

Methods: A prospective follow-up study performed at the St.Olav's University Hospital, Trondheim, Norway. Thirty-four infants were included with mean gestational age 27.5weeks (SD 3.0w) and mean birth weight $1008 \mathrm{~g}$ (SD 462g). The GMA was performed at mean 15 weeks post term. Fidgety movements were classified as absent (F-) or present (normal $(\mathrm{F}+)$, no-continuous $(\mathrm{F}+/-)$, or abnormal (AF) fidgety). At age 10 the Wechsler Intelligence Scale for Children-III (WISC-III) was performed to assess IQ-status. Differences in group means were compared.

Results: Six infants had F- and all of them developed CP at age 10. Two of three children with F+/- had CP. One child with F+ had CP.

Cognitive results are shown in table 1 .

\begin{tabular}{|c|c|c|c|}
\hline IQ measure & Absent fidgety & Present fidgety & $p$ \\
\hline & $n=6$ mean & $n=28$ mean & \\
\hline Total-IQ & 57.2(SD 25.5) & 95.7(SD 21.7) & 0.024 \\
\hline Verbal-IQ & 69.2(SD 24.0) & 95.3(SD 18.3) & 0.044 \\
\hline Working-memory-index & 68.3(SD 17.5) & 92.4(SD 16.9) & 0.018 \\
\hline Performance-IQ & 48.0(SD 20.2) & 97.2(SD 22.1) & 0.001 \\
\hline $\begin{array}{l}\text { Perceptual-organization- } \\
\text { index }\end{array}$ & 59.2(SD 14.5) & 97.3(SD 20.3) & 0.001 \\
\hline
\end{tabular}

[Table 1]

Conclusions: Preterm born children without fidgety at 15 weeks post term had cerebral palsy and lower total- and verbal-IQ as well as working-memory deficits at age 10 . 